\title{
Media Competitiveness of Live TV News
}

\author{
Shuai Gao \\ School of Theater, Film and Television \\ Communication University of China \\ Beijing, China
}

\begin{abstract}
A live coverage of a major news event can help the media gain reputation and long-term influence. The core of long-term, high-capacity TV live broadcast report is to form an information flow, rather than just continuous reporting. Television was born for live coverage. Whoever can report news more quickly and continuously is able to become the first choice, first dependency, and first source of information for people when major emergencies occur.
\end{abstract}

Keywords-television news; live coverage; major emergencies; media competitiveness

\section{INTRODUCTION}

The connotation of TV live broadcast "Chinese Applied Television Study" thinks that live broadcast refers to the "real-time broadcast mode that converts images, sounds of news, journalists' reports, interviews, etc. into direct transmission of instant television programs. As for news event, it is both a report mode and a broadcast program.

The so-called live broadcast refers to the "broadcasting mode of producing and broadcasting radio and television programs at the same time with the occurrence and development of the event." Unlike recorded broadcast, the live broadcast reporting process is the broadcasting process, and the reporting and broadcasting go on simultaneously.

The number and quality of live TV news live broadcasts is one of the standards to measure how much progress has been made in the reform of TV news in China. The positive change in the environment of public opinion has provided greater possibilities for the richness and diversity of live TV news programs; constantly adjusting the concept of live broadcasting, standardizing the professionalization of live broadcast operations, and improving the mobility of live broadcast operations are the top priorities for enhancing the effectiveness of live broadcast. Media managers' control on live broadcasts depends on the recognition of media operators, the correct judgement of audience's information need, and a conscious understanding of the media environment and the media competitiveness state.

Hence, the live broadcast of TV news is one of the standards to measure the progress and achievements of TV news reform. The live broadcast of TV news is the result of news reform. The number and quality of live TV news broadcast programs is one of the standards to measure the progress of Chinese TV news reform as well as the achievements of TV news reform. Television live broadcast of major news events is an important way for TV stations to gain media competitiveness.

\section{LiVE BROADCAST CAN BeSt REFLECT THE MEDIA COMPETITIVENESS OF TV MEDIA}

Though seems original and direct, live broadcast is actually the ultimate product that condenses all types of TV journalism and has been used to its utmost. Of course, those ultimate products refer to excellent live TV news works, such as the program system (host, Director, camera, feature film, studio series, program image packaging, etc.), and the technical systems (video, audio, communication, transmission, power, microwave, satellite lines, light lines, etc.). Any mistakes happened in the types or links of the works mentioned above are unacceptable mistakes once reflected on the screen.

For a long time, the impression left by local TV broadcasts on Chinese audiences can be described as "gorgeous": sufficient preparation time, numerous camera positions, and magnificent visual scenes. Because of the "luxurious", live television has become a luxury in all kinds of TV programs, which is seldom used. The large use of live news in Wenchuan Earthquake finally let Chinese live television become less luxurious and gain media competitiveness.

The majority of TV media adopted the live broadcast mode in the report of Wenchuan earthquake relief in 2008. The significance of live broadcast of TV news at present is that there are multi-camera stands at the news site, and the live editing system is directly connected to the satellite editor to the broadcast, which presents the live news transmission as main body while integrating with multi-site switching exchange such as comprehensive background information, relevant knowledge introduction, the connection of a series of studios, comments and field reporter interview. In recent years, because of the media events are often used by television stations as a symbol to measure their ability to report on the news, various topics are advanced, and propositions emerge endlessly. In turn, the audience has ignored the reporting capabilities of news events by video land.

While the live coverage of TV news records the development and changes of news events, the broadcasts of live reports by reporters, the live descriptions or background introductions by announcers or hosts are communicated simultaneously. The live coverage of TV news integrates 
reporting news, knowledge, and event analysis. Meanwhile, news events are divided into sudden news events and anticipated events. Among different types of events, higher requirements for television media's overall capabilities are proposed.

On May 12, the CCTV news channel reported Wenchuan earthquake 32 minutes later after the earthquake happened, and then a special live program "Following the Wenchuan Earthquake" was launched 52 minutes later, from 15:20, May 12 to 20:00, May 13, spanning over 26 hours. The live was broadcast day and night on the same topic uninterruptedly. Meanwhile, since 22:00 on May 12, simultaneously broadcast by both CCTV-1 and CCTV-News is realized. The live program firstly broadcast more than 200 pieces of news, which made live broadcast become the main access to obtain news in the earthquake region information for both Chinese and international news media. The live report satisfied audience's information needs at first time, and the immediate authoritative announcement refuted rumors about the earthquake in time, which stabilized the hearts of the people.

Multiple CCTV channels immediately reported the earthquake by rolling news. The objective, efficient, balanced, and transparent reporting has won discourse power in television media for the first time, and has played a good role in guiding public opinion. Overseas media have widely adopted CCTV international channel program's signals. Up to now, 298 television organizations in 113 countries and regions have used or partially used CCTV's Chinese international channel, English channel, French channel, and Spanish channel signals to broadcast. Of these television organizations, 107 rebroadcast Chinese international channel programs, 231 rebroadcast English channel programs, 10 rebroadcast French channel programs, and 7 rebroadcast Spanish channel programs. In total, there are 239 television organizations rebroadcast all programs and 59 rebroadcast partially. $\mathrm{CNN}$ and $\mathrm{BBC}$ quote reports mostly from the Xinhua News Agency, CCTV, Sichuan TV and other relevant Chinese media. The government's rapid response to crisis management and the openness of information enables China to obtain the initiative in foreign reporting.

\section{ThE LiVE BRoAdCAST CAN MOST REPRESENT THE DEVELOPMENT DIRECTION OF TV NEWS}

While possessing news resources, it is a question that how to express those resources to make audience recognize and accept. Live broadcast is undoubtedly the most attractive expression. No time difference and no error of the live broadcast let the audience feel the most direct timeliness, integration and reality. As a media with strong propagation characteristics, even if the news is broadcast after the fastest editing, the authenticity of the news will inevitably be questioned by the audience. The reform of TV news has undergone and is undergoing a change of concept from program to column to channel. The launch of the CCTV news channel provides a larger platform and space for live broadcast of TV news. Live broadcast reports are regarded as a means to show the strength and advantages.

The scales of report response of CCTV's programs the Iraq War in 2003 and the terrorist attacks in the United States in 2001, September 11th are carefully compared as shown in "Table I".

TABLE I. ThE SCALES OF REPORT RESPONSE OF CCTV'S PROGRAMS

\begin{tabular}{|l|l|l|}
\hline & \multicolumn{1}{|c|}{ The outbreak of Iraq War } & The September 11, 2001 terror attacks in the US \\
\hline Occurrence time & $10: 35$ & $20: 45$ \\
\hline CNN Reports & $10: 40$ & $20: 50$ \\
\hline CCTV 1 & $10: 43$ & $21: 13$ \\
\hline First report form & $\begin{array}{l}\text { Interrupts normal programs then makes } \\
\text { live broadcasts }\end{array}$ & Reports in the "Broadcast Now" program \\
\hline First report duration & 4 hours and 47 minutes & 19 seconds \\
\hline $\begin{array}{l}\text { Overall reports duration } \\
\text { per 24 hours }\end{array}$ & 12 hours and 30 minutes & 1 hour and 28 minutes \\
\hline $\begin{array}{l}\text { Government statement of } \\
\text { first report }\end{array}$ & $\begin{array}{l}4 \text { hours and 20 minutes after the } \\
\text { occurrence }\end{array}$ & 4 hours and 25 minutes after the occurrence \\
\hline
\end{tabular}

Above statistics shows that although the first point was seized and the first timeliness of the report was ensured, due to the failure to maintain an appropriate scale of reporting, to make full use of the TV reporting characteristics to timely launch live broadcast, and to satisfy the grand public's thirst for follow-up information, some qualified audiences thus turned to overseas stations, which cause losing and missing of good publicity opportunities.

Language generated tribes, words established nations, and electronic media represented by television and internet made the world "global village". The concept of "global village" requires and reminds us again that preemption is the iron law of communication. There must never be an information vacuum. The more important the emergency, the fasterand more timely is required as live broadcast is a simple and convenient means.

With regard to the Wenchuan earthquake report, the media's "first time" reporting awareness increased, and CCTV broadcast the latest news. Errors are corrected at any time when they are found. No one has questioned this situation because the public fully understand the situation that such correction mechanism in normal process of news dissemination. About the magnitude of the earthquake, CCTV reported its first earthquake news on May 12th at 15:02 that a magnitude 7.6 earthquake occurred in Wenchuan County, Sichuan. After that, the local CCTV departments continued to collect information from local television stations. When confirming that the news of the 
magnitude 7.0 earthquake in Zhejiang and the magnitude 3.9 earthquake in Tongzhou, Beijing were misinformation, the host immediately corrected it. Shortly afterwards, China Earthquake Administration updated the Wenchuan earthquake magnitude to 7.8. The host corrected it again. On May 18, China Earthquake Administration revised the magnitude to 8.0, and CCTV corrected it one more time.

Repeated corrections by the media do not mean irresponsible for the truth of the news. On the contrary, immediate reporting and subsequent corrections are the manifestation of the media's maturity. Of course, showing the truth of news dynamically does not mean that the media can ignore the truth of the facts. when refers to certain facts that are relevant to overall situation and may cause immediate adverse effects, it is particularly important to form a set of review systems to prevent such information release from unnecessary loss. However, such situation should be regarded as an exception but not as a general rule. In addition, for some more specific facts, under the conditions of limited information sources and time, the media's appropriate vagueness (leave some leeway) for factual reports is more authentic than precise reports.

The earthquake happened when "People's Republic of China Government Information Disclosure Bill" came into effect for just less than a month. The Wenchuan earthquake was undoubtedly a severe ordeal after the implementation of the regulations. The media is the disseminator of "information disclosure". In this dissemination process, no time difference and no loss are particularly important. The live broadcast is the scale of news reform, and the live broadcast of emergencies is the index dial of this scale.

It is remembered that CCTV's first information about the earthquake was broadcast by News Updates in news channel. At that time, the announcer Sa Geng broadcast the news of the Wenchuan, Sichuan earthquake in just one sentence. Soon after, the news channel initiated a live broadcast. Because there were no scenes sent back from the field and no reporters appeared in the news at first, the studio adopted interviews between the host and relevant experts, as well as connections with reporters from local TV stations in Sichuan. Under the circumstances that the scenes are absent, the news of the earthquake in Wenchuan, Sichuan was rolling at the bottom of the screen. The live program "Earthquake Relief Surmount" produced by news channel was consistently played until 2:00 am every day for half a month after the earthquake.

\section{IV. "NEWS IS A WINDOW FOR PEOPLE TO KNOW THE WORLD"}

The sociologists insist that people should be regarded as social actors. Traditional sociologists prefer to take people's activities as standardized socialized behaviors, and these standards come from the objective characteristics of social structure. In Short, the society creates the consciousness. By contrast, the recent interpretive sociologies argue that the social world provides norms for actors. Whether social actors use these norms as a resource or as a limiting factor, they implement self-plans through their positive activities. And in turn, the social world and its institutions constitute a shared phenomenon. The two processes are synchronous--on the one hand, society helps the formation of consciousness, and on the other hand, people construct social phenomena jointly through conscious and active activities in the shared social world.

Compared with text media, the biggest advantage of TV news is that it can vividly, comprehensively reproduce and restore news events through various means such as images, sounds, and subtitles. Though thousand miles away, the instant information became close at hand. People are able to see and hear news that just happened, even the news that is happening. Nowadays, the demands of TV audiences for the timeliness of news have changed from "TNT" (Today's News Today) to "NNN" (Now News Now). In order to maximize the origins of news from the timeline, the current trend of TV news development is to use live broadcasts as much as possible, so that viewers can see its development and changes at the same time as news events occur. From the perspective of the communication process, the live TV broadcast synchronizes the news events with the objective news events when the directors receive the information. The attenuation of the information can be minimized, and the authenticity of the news is unquestionable. In contrast, it is impossible for TV to bring viewers close to news events on the axis of space, because TV viewers cannot really reach the news site, but TV has the advantages of both audiovisual, audiovisual, intuitive scenes, vivid details, and strong live The sense of participation, sense of participation and immersion attracted the audience and made up for the lack of physical intervention with strong psychological feelings. The TV live broadcast has characteristics of synchronization in time and proximity in space. Through visual and auditory channels, the TV live broadcast achieved another return in the spiral of mass communication, which make the TV news return to its origin. The vivid television images have incorporated the basic characteristics of interpersonal communication, such as psychological communication, emotional interaction, and belonging identity, into mass communication, thereby the authenticity of news is improved.

Taking the Wenchuan earthquake report as an example when looking back Chinese television's actions to face the disaster, the live broadcast of the earthquake relief work can be said to have turned over a new leaf in China disaster reporting history. In the history of Chinese live coverage, the biggest difference between this and previous reports lies in this one is the first China disaster report. This is the beginning of reporting disasters in a real sense, and the new start for Chinese media.

\section{CONCLUSION}

The live broadcast allowed us to see the development of the voice of live TV. The broadcast used to focus on the sender while now is audience, which reflects a change in the concept of communication. The audience no longer passively receives the fragments and results of the events reported by the media, but pay more attention to the details and the information behind the events. The content of the media has also been greatly improved as it no longer simply spread 
ideological things, thus made television more ornamental. At the same time, the media's reporting has achieved a transformation from unitary style to multivariate styles. Success has followed the path of failure. The eight-year course of CCTV live broadcast has achieved the calmness and atmosphere of live broadcast today. The live TV broadcast goes with the times and has recorded a series of precious historical pictures. With its unique advantages, live broadcasting is providing audiences with "the first-time wonderfulness", and has also established its irreplaceable strong position among various television broadcast methods.

\section{REFERENCES}

[1] Han Biao. Live Broadcast - A Standard to Measure News Reform [M] (in Chinese). Contemporary China Publishing House, 2007. (in Chinese)

[2] Zhu Yujun, Lei Weizhen. The Science of Television Interview [M] (in Chinese). People's Publishing House, 2003. (in Chinese)

[3] Song Xiaoyang. Live Coverage Guide for Onscreen Journalists [M] (in Chinese). China Radio Film \& TV, 2008. (in Chinese)

[4] Shi Changshun. Practical Tutorials for Contemporary Television [M] (in Chinese). Fudan University Press, 2005. (in Chinese)

[5] [US] Bod Edwards, et al. Edward R. Murrow and The Birth of the American Radio and Television Journalism [M]. Translated by Zhou Peiqin. Fudan University Press, 2005.

[6] Ye Zi. Television News:Keep up with Events [M] (in Chinese). Beijing Normal University Publishing Group, 2007. (in Chinese) 